\title{
Technology that achieves the Triple Aim: an economic analysis of the BrainPath ${ }^{\mathrm{TM}}$ approach in neurosurgery
}

\section{Sidney P Norton' \\ Evan M Dickerson' \\ Charles G Kulwin² \\ Mitesh V Shah ${ }^{2}$}

'Financial Planning and Analysis, Indiana University Health, Indianapolis, IN, USA; ${ }^{2}$ Adult Neurosurgery, Goodman Campbell Brain and Spine, Indianapolis, IN, USA

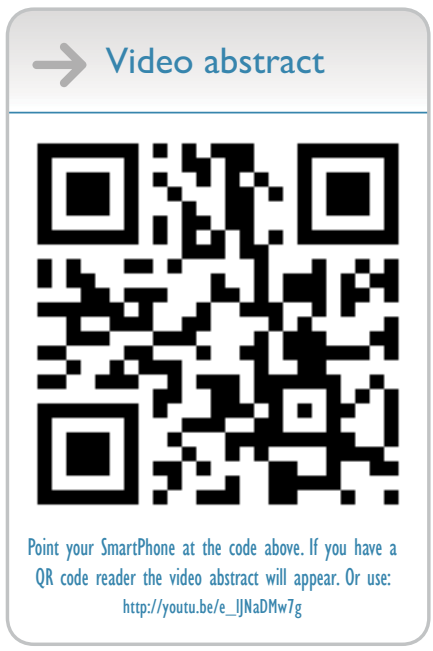

Correspondence: Sidney P Norton Cincinnati Children's Hospital Medical Center, 3333 Burnet Avenue, MLC 3018, Cincinnati, OH 45229 USA

$\mathrm{Tel}+$ I 5 I3803 1064

Email sidney.norton@cchmc.org
This article was published in the following Dove Press journal:

ClinicoEconomics and Outcomes Research

26 August 2017

Number of times this article has been viewed

Background: The Triple Aim is defined as: improving the patient experience of care, improving the health of populations, and reducing the per capita cost of health care. The purpose of this analysis was to evaluate the economic value of a new neurosurgical technique, the BrainPath ${ }^{\mathrm{TM}}$ approach, for use in patients with subcortical tumors and intracerebral hemorrhage (ICH).

Methods: Inpatient length of stay (LOS) data were collected for $\mathrm{ICH}$ and brain tumor surgical patient cases between August 2013 and November 2015. Patient cases were separated into two groups; BrainPath approach $(\mathrm{n}=28)$ and conventional techniques, such as craniotomy, $(\mathrm{n}=208)$. The average intensive care unit (ICU) LOS was calculated for each group by diagnosis-related group and compared between groups.

Results: The new surgical technology resulted in surgical intervention in $14 \mathrm{ICH}$ cases which otherwise would have been medically managed due to the hemorrhage location or size of the ICH. A reduction in ICU LOS was seen in this group. Based on the variable direct cost per day in the neuro critical care unit at this academic medical center, 14 patient cases incurred $\sim$ US\$210,000 less in direct ICU costs. Surgical resection was possible in two tumor patient cases which would have been biopsied, rather than surgically resected, also due to location of the abnormalities. A total net value of $>$ US\$329,000 is attributable to the analyzed approach over a 28-month period.

Conclusion: This analysis shows positive economic value for the new technology group when ICU LOS and reimbursement are considered against equipment costs, thus achieving Triple Aim objectives.

Keywords: brain tumor, intracranial hemorrhage, intracerebral hemorrhage, intensive care unit length of stay, Triple Aim, economic value

\section{Introduction}

Hospitals are under the pressure of declining reimbursement, while simultaneously being held to increasing quality standards. Higher patient deductibles and the availability of comparative medical information are motivating patients to become more involved in decisions about their health care. The combination of these forces has resulted in a challenge referred to as the "Triple Aim". The Triple Aim is defined as: 1) improving the patient experience of care (including quality and satisfaction); 2) improving the health of populations; and 3) reducing the per capita cost of health care. ${ }^{1}$

The shift in health care economics will drive out the providers who are unable to meet the increasing demands of patients and quality standards. For example, in the operating room, higher cost technologies can no longer be justified based on surgeon 
preference or marginal improvements in outcomes. Trading off one Triple Aim component for another, such as increasing patient satisfaction but at a higher per capita cost, will not be sufficient. As academic medical centers strive to innovate and lead in the advancement of medical technology, expenditures on new technologies must be justified by meeting all the criteria of the Triple Aim.

In particular, there is a tremendous need for economic analysis to inform the practice of neurosurgery about the potential economic benefit of adopting new technology. In an editorial published in 2014, McLaughlin et al state, "massive structural pressures will force a stronger accounting of health care costs and demand more efficient neurosurgical practice in a resource-constrained environment." ${ }^{2}$ They also point out "from 1996-2010, among PubMed-Indexed 'neurosurgical' papers, only $2.8 \%$ evoked costs but did not necessarily include a health economics evaluation." 2 The purpose of this analysis is to evaluate a new neurosurgical technology with the intent of confirming that it achieves the Triple Aim. This study specifically addresses the costs of care and the patient experience of care. In this analysis, the economics of the BrainPath ${ }^{\mathrm{TM}}$ (Nico Corporation, Indianapolis, IN, USA) surgical approach and technology are evaluated against patient cases in the same diagnosis-related group (DRG) which did not use the technology. The goal was to determine if the changes in the approach and technology resulted in economic value to the hospital, improved patient experience, and improved patient outcomes, after accounting for the incremental cost of using the device, thereby achieving the Triple Aim.

The work presented in this paper was covered by Institutional Review Board (IRB) number 1510626355 "BrainPath Experience with Deep Intracerebral Neurological Monitoring”, approved by the Indiana University IRB. In this IRB submission, the investigators were solely doing retrospective data collection and had a waiver for informed consent because most of the patients were outside the followup timeframe and were no longer being seen in the clinic. In compliance with HIPAA, only de-identified data were used in this research.

BrainPath is a minimally disruptive access technology approved by the US Food and Drug Administration to provide access and allow for visualization of the surgical field during brain and spinal surgery. Indications may include subcortical access to diseases such as primary and secondary brain tumors, vascular abnormalities and malformations, and intraventricular tumors and cysts. ${ }^{3}$ Using a dime-sized dural opening, the surgeon can reach and remove tumors and intracerebral hemorrhages (ICHs) with less impact on intervening healthy brain tissue. Utilization of this technology and technique requires proctored training. The clinical outcome improvements achieved via this technique have been established separately in clinical literature. ${ }^{4}$

\section{Methods}

The new surgical technology has been used in ICH and brain tumor surgeries. Methods and results for each are presented separately.

\section{$\mathrm{ICH}$ data set}

All ICH patient cases with Medicare Severity - Diagnosis Related Group (MS-DRG) codes 3-4 and 23-24 from August 2013 to November 2015 were screened. Through a physiciandirected clinical review of the patient records, outliers were excluded if they would not have been surgical candidates based on the condition of the patient (e.g., tracheostomy patients), size of the hematoma, or other clinical variations. Intensive care unit (ICU) length of stay (LOS) and reimbursement data were collected for each patient. The cases were grouped based on MS-DRG in order to compare patient cases done using traditional methods (e.g., craniotomy) to those done using the new minimally disruptive technique.

\section{Brain tumor data set}

All brain tumor patient cases with MS-DRG codes 25-27 from August 2013 to November 2015 were screened. ICU LOS and reimbursement data were collected. The cases were grouped based on DRG in order to compare surgical cases done using traditional methods (e.g., craniotomy) to those done using the new minimally disruptive technique.

\section{Calculations and statistical analysis Average ICU LOS}

For each group, the average ICU LOS was calculated by summing the total ICU days and dividing by the number of patient cases. The average ICU LOS for each traditional method group was compared to the average of the new technology group.

\section{Reduction in ICU days}

The reduction in hospital ICU days attributable to the BrainPath approach was estimated by multiplying the number of patients by the difference in the average ICU LOS between traditional and new technology groups. 


\section{Cost savings calculation}

The variable direct cost of a day of neurological critical care in the review facility has been calculated to be $\$ 2,007$. In the facility overall, variable direct costs represent $65 \%$ of total expenses. The full cost of an ICU day is therefore estimated to be $\$ 3,088$. These values were multiplied by the reduction in ICU days to arrive at estimated hospital savings from all patient cases done using the new surgical technology. The disposable technology included within the approach costs $\$ 4,000$ per surgery.

\section{Significance}

Because of the small sample size, non parametric statistical tests were used to compare baseline and demographic data between the BrainPath and the traditional groups. Baseline patient characteristics (age, gender, race, marital status, readmission, and status upon discharge) were examined for a relationship between categorical variables using Chi-square statistic or Fisher's exact test where appropriate. Differences in means for LOS, ICU days, and ventilations days were examined for statistical significance using the Mann-Whitney $U$ test for independent samples. ${ }^{5}$

\section{Results}

\section{Intracranial hemorrhage}

Patients

Table 1 summarizes the patient demographics of the BrainPath and traditional patient cases. There was no statistically significant difference between the patient groups.

In patients with DRG 23-24, the 14 BrainPath patient cases had an average ICU LOS of 4.4 days versus 11.9 days ( $\Delta=7.5$ days, $p=0.01$, Table 2 ). Applying only variable direct costs to the reduction in ICU days for all 14 BrainPath patient cases yields a saving of $\$ 210,735$. With an average decrease of nearly a week of ICU care in these patients, it is likely that some fixed costs could also be impacted. Using $\$ 3,088$ as the full cost of an ICU patient day, $\$ 4,000$ as the cost of the BrainPath disposable, and 7 days as the average ICU LOS difference, surgical cases done with the new technology have a potential marginal saving of $\$ 17,614$ per patient compared to the traditional method cases.

A second area of value which was not initially evident in the LOS analysis was identified in the form of additive surgical cases, meaning the technology made it possible for surgical treatment in those patients with deep abnormalities, or abnormalities near critical areas of the brain. All 14 BrainPath ICH patients would have been medically managed at our institution if this technology had not been available. An investigation of
Table I Patient demographics - ICH patients

\begin{tabular}{|c|c|c|c|}
\hline Demographic & BrainPath & Traditional & $p$-value \\
\hline Cases & 8 & 41 & \\
\hline Age, years & & & 0.314 \\
\hline $17-49$ & 3 & II & \\
\hline $50-69$ & 2 & 22 & \\
\hline$>70$ & 3 & 8 & \\
\hline Gender & & & 0.706 \\
\hline Male & 5 & 21 & \\
\hline Female & 3 & 20 & \\
\hline Race & & & 0.486 \\
\hline Asian & 0 & I & \\
\hline Black & 2 & 4 & \\
\hline White & 6 & 31 & \\
\hline Other/unverified & 0 & 5 & \\
\hline Marital status & & & 0.727 \\
\hline Divorced/separated & 0 & 4 & \\
\hline Married & 4 & 23 & \\
\hline Single & 3 & 10 & \\
\hline Widowed & I & 4 & \\
\hline 30-day readmission & & & 0.430 \\
\hline Readmission in 30 days & 0 & 3 & \\
\hline No readmission in 30 days & 8 & 38 & \\
\hline Status upon discharge & & & 0.663 \\
\hline Alive & 7 & 29 & \\
\hline Deceased & I & 12 & \\
\hline
\end{tabular}

Note: BrainPath ${ }^{\mathrm{TM}}$, Nico Corporation, Indianapolis, IN, USA. Abbreviation: $\mathrm{ICH}$, intracerebral hemorrhage.

Table 2 ICU days reduction in ICH patients

\begin{tabular}{|c|c|c|c|}
\hline & \multicolumn{2}{|c|}{ MS-DRG 23-24 } & \multirow[t]{2}{*}{$p$-value } \\
\hline & Traditional & BrainPath $^{\mathrm{TM}}$ & \\
\hline Number of patients & $4 \mid$ & 14 & \\
\hline Average ICU days & 11.9 & 4.4 & 0.01 \\
\hline Reduction in ICU days & & 105.0 & \\
\hline $\begin{array}{l}\text { Variable direct cost savings } \\
(\$ 2,007 / \text { day })^{*}\end{array}$ & & $\$ 210,735$ & \\
\hline Estimated savings $(\$ 3,088 / \text { day })^{a}$ & & $\$ 324,208$ & \\
\hline
\end{tabular}

Notes: ${ }^{2}$ Cost savings is estimated in United States dollars (\$) based on the variable direct cost of a day in the neurological critical care calculated as $\$ 2,007$ per day. A value of $\$ 3,088$ was assumed for the full cost, including fixed overhead and allocations, of an ICU patient day. ${ }^{3}$ BrainPath ${ }^{\mathrm{TM}}$, Nico Corporation, Indianapolis, IN, USA. Abbreviations: ICU, intensive care unit; ICH, intracerebral hemorrhage; MS-DRG, Medicare Severity - Diagnosis Related Group.

the cost and reimbursement of surgical ICH cases compared to medical cases (DRG 64-66) shows an incremental margin of $\$ 8,089$ for each surgical case. Therefore, in addition to the savings of reduced ICU LOS, the hospital received $\sim \$ 113,250$ in incremental margin from the use of the analyzed technology in these 14 patients.

\section{Brain tumor}

\section{Patients}

Table 3 summarizes the patient demographics for the BrainPath and traditional patient cases. The groups were statistically similar in all patient demographics except race. 
Table 3 Patient demographics - brain tumor patients

\begin{tabular}{|c|c|c|c|}
\hline Demographic & BrainPath $^{\mathrm{TM}}$ & Traditional & $p$-value \\
\hline Cases & 10 & 167 & \\
\hline Age, years & & & 0.646 \\
\hline $17-49$ & 6 & 88 & \\
\hline $50-69$ & 4 & 66 & \\
\hline$>70$ years & 0 & 13 & \\
\hline Gender & & & 0.319 \\
\hline Male & 8 & 99 & \\
\hline Female & 2 & 68 & \\
\hline Race & & & $>0.001$ \\
\hline Asian & 0 & 1 & \\
\hline Black & 0 & 5 & \\
\hline White & 10 & 156 & \\
\hline Other/unverified & 0 & 6 & \\
\hline Marital status & & & 0.462 \\
\hline Divorced/separated & 0 & 18 & \\
\hline Married & 8 & 96 & \\
\hline Single & 2 & 44 & \\
\hline Widowed & 0 & 9 & \\
\hline 30-day readmission & & & 0.247 \\
\hline Readmission in 30 days & 2 & 15 & \\
\hline No readmission in 30 days & 8 & 152 & \\
\hline Status upon discharge & & & 0.100 \\
\hline Alive & 7 & 149 & \\
\hline Deceased & 3 & 18 & \\
\hline
\end{tabular}

Note: BrainPath ${ }^{\mathrm{TM}}$, Nico Corporation, Indianapolis, IN, USA.

In patients with DRG 25-27, BrainPath patient cases had an average ICU LOS of 1.0 days versus 1.8 days $(\Delta=0.8$ days, $p=0.07$, Table 4). Using $\$ 2,007$ as the variable direct cost of an ICU patient day and $\$ 4,000$ as the cost of the BrainPath disposable device, cases done with the BrainPath approach do not result in a net saving. Because tumor surgeries in the data set average $<2$ ICU days, the reduction of $\sim 1$ day does not exceed the $\$ 4,000$ cost of the disposable device.

\section{Discussion and conclusion}

For patients with $\mathrm{ICH}$, there was a statistically significant reduction in ICU days for BrainPath patient cases versus traditional patient cases. Applying only variable direct costs to the reduction in ICU days for the BrainPath patient cases yields a savings of $\$ 210,735$. With an average decrease of nearly a week of ICU care in these patients, it is likely that some fixed costs could also be impacted. For patients with brain tumor, BrainPath patient group demonstrated a shorter average ICU LOS than the traditional method patients, resulting in a 50\% reduction in ICU LOS, however, this difference was not statistically significant.

Review of the BrainPath tumor cases revealed surgical value in this population despite the modest reduction in ICU LOS. Because the neurosurgeon could safely access the
Table 4 ICU days reduction in brain tumor patients

\begin{tabular}{llll}
\hline & \multicolumn{3}{l}{ MS-DRG 25-27 } \\
\cline { 2 - 4 } & Traditional & BrainPath & P-value \\
\hline Number of patients & 167 & 14 & \\
Average ICU days & 1.8 & 1.0 & 0.07 \\
Reduction in ICU days & & 11.2 & \\
Variable direct cost savings & & $\$ 22,478$ & \\
$(\$ 2,007 / \text { day })^{\mathrm{a}}$ & & & \\
\hline
\end{tabular}

Notes: aCost savings is estimated in United States dollars (\$) based on the variable direct cost of a day in the neurological critical care calculated as $\$ 2,007$ per day. A value of $\$ 3,088$ was assumed for the full cost, including fixed overhead and allocations, of an ICU patient day. ${ }^{3}$ BrainPath ${ }^{\mathrm{TM}}$, Nico Corporation, Indianapolis, IN, USA

Abbreviations: ICU, intensive care unit; MS-DRG, Medicare Severity - Diagnosis Related Group.

deep-seated abnormalities via the approach, surgical resection was performed in two tumor patients who would have otherwise been biopsied and treated medically. An investigation of the cost and reimbursement of tumor resection cases compared to frameless stereotactic biopsy alone shows an incremental margin of $>\$ 9,761$ for each surgical case. Therefore, the hospital received $\sim \$ 19,500$ in incremental margin from the use of the analyzed technology in these two patients. More importantly, the surgeons felt there was clinical benefit to the patient by using the less invasive approach, and the combination of these collective benefits enables achievement of the Triple Aim of health care.

All hospitals are faced with the challenge of managing budgets by department, while also looking at the health care system as a whole. The goal of this analysis is to look at economics across departments in order to make a better system-wide decision on the true value of technology. Even though the BrainPath approach increases the marginal cost of the surgical procedure, this investigation's results show that the procedure cost is more than offset by the reduction in ICU LOS. Nevertheless, a complete analysis must account for the total costs and savings from adopting the new technology, which includes capital equipment. The necessary capital expenditure is comprised of the Myriad console costing $\$ 139,500$ and the BrianPath kit costing $\$ 22,500$. The net economic benefit is shown in Table 5. These data were calculated using simple straight-line depreciation with a 10-year useful life (assuming a monthly depreciation expense of $\$ 1,350$ ) and a time period of 28 months. BrainPath demonstrated a net financial value to the academic institution of $\$ 329,659$.

The purpose of this analysis was to determine if there was an overall economic benefit to the hospital system from the adoption of new surgery technology in neurosurgery. Similar financial analyses often focus too narrowly on the cost of a procedure and may overlook the economic value which arises 
Table 5 Net estimated economic benefit with BrainPath ${ }^{\mathrm{TM}}$

ICU days at full cost for ICH cases

$\$ 324,208$

Marginal reimbursement from I4 ICH surgical cases

$\$ 113,250$

ICU days at variable direct cost for brain tumor cases

$\$ 22,478$

Marginal reimbursement from two tumor surgical cases

$\$ 19,523$

BrainPath disposable cost for 28 cases

Depreciation expense $\times 28$ months

$\$(112,000)$

$\$(37,800)$

Net estimated economic benefit of BrainPath technology ${ }^{\mathrm{a}}$

$\$ 329,659$

Notes: Calculations in US dollars. Based on the variable direct cost of a day in the neurological critical care unit calculated as $\$ 2,007$ per day and the full cost as $\$ 3,088$ per day. A monthly depreciation expense of $\$ 1,350$ over 28 months was assumed. BrainPath demonstrated a net financial value to the investigator's academic institution of $\$ 329,659$. BrainPath ${ }^{\mathrm{TM}}$, Nico Corporation, Indianapolis, IN, USA.

Abbreviations: ICU, intensive care unit; $\mathrm{ICH}$, intracerebral hemorrhage.

in other areas. This results in a perceived trade-off between improved patient outcome and higher cost.

As health care moves toward a new environment of population health and bundled payments, achieving the Triple Aim is essential. In making decisions of whether to adopt new technologies, health care systems need to look at the entire episode of care. This includes understanding how a new technology impacts downstream patient expenses and reimbursement. Within this investigation, combined with published clinical results, positive outcomes are observed in all three objectives of the Triple Aim. Ultimately, significant reductions in ICU LOS improve the patient experience of care, demonstrate an improvement in the health of these patient populations, and reduce the per capita cost of health care.

Limitations of this study include inability to directly compare the two groups analyzed for comparable admission characteristics, aside from general admission diagnosis code. If the conventional techniques group was significantly sicker than the BrainPath approach group, the ICU LOS difference could be less attributable to this technique. Conversely, if the
BrainPath approach group consisted of sicker patients, the magnitude of improvement attributable to the approach may be underestimated. Nevertheless, ICU LOS is a clinically driven metric, representing a source of major health care cost; thus a reduction in ICU LOS represents a high value target for clinically driven cost savings.

Additionally, our cost savings analysis is a model based on average cost and therefore could under or overestimate the actual health care costs or savings of each individual patient.

This analysis did not attempt to track reductions in inpatient complications, such as thromboembolic events or hospital-acquired infections. Shorter ICU stays may correlate with fewer such events, also improving the health of the population and reducing per capita health care costs. Lastly, further research comparing readmission rates and clinical outcomes post-discharge would enhance the economic evaluation.

\section{Disclosure}

The authors report no conflicts of interest in this work.

\section{References}

1. Institute for Healthcare Improvement [homepage on the Internet]. IHI Triple Aim Initiative. Available from: http://www.ihi.org/engage/initiatives/TripleAim/Pages/default.aspx. Accessed June 5, 2017.

2. McLaughlin N, Khalessi AA, Martin NA. Health care economics in neurosurgery: there is no turning back. Neurosurg Focus. 2014;37(5):E1.

3. US Food and Drug Administration [homepage on the Internet]. FDA 510k Clearance for BrainPath. Available from: http://www.accessdata. fda.gov/scripts/cdrh/cfdocs/cfpmn/pmn_template.cfm?id=k150378. Accessed June 5, 2017.

4. Labib MA, Shah M, Kassam AB, et al. The safety and feasibility of image-guided BrainPath-mediated transsulcul hematoma evacuation: a multicenter study. Neurosurgery. 2017;80(4):515-524.

5. D'Agostino RB, Sullivan LM, Beiser AS. Nonparametric Tests. In: D'Agostino RB, Sullivan LM, Beiser AS. Introductory Applied Biostatistics. Brooks Cole; 2006:545-583.
ClinicoEconomics and Outcomes Research

\section{Publish your work in this journal}

ClinicoEconomics and Outcomes Research is an international, peerreviewed open-access journal focusing on health technology assessment, pharmacoeconomics and outcomes research in the areas of diagnosis, medical devices, and clinical, surgical and pharmacological intervention. The economic impact of health policy and health systems

\section{Dovepress}

organization also constitute important areas of coverage. The manuscript management system is completely online and includes a very quick and fair peer-review system, which is all easy to use. Visit http://www.dovepress.com/testimonials.php to read real quotes from published authors.

Submit your manuscript here: https://www.dovepress.com/clinicoeconomics-and-outcomes-research-journal 